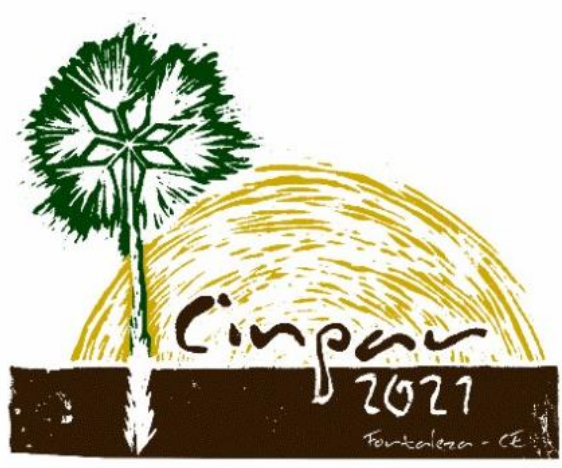

XVII Congresso Internacional sobre Patologia e

Reabilitação das Construções

XVII Congreso Internacional sobre Patología y Rehabilitación de las Construcciones

XVII International Conference on Pathology and Constructions Rehabilitation

FORTALEZA (Brasil), 3 a 5 de junho de 2021

https://doi.org/10.4322/CINPAR.2021.036

\title{
Análise das manifestações patológicas em escola pública do município de Apodi/RN
}

\author{
Lourena Barbosa Cavalcante PAIVA ${ }^{1}$, Joice Alves da COSTA ${ }^{2}$ \\ ${ }^{1}$ Universidade Federal Rural do Semi-Árido - UFERSA, Caraúbas-RN, Brasil, lourena_paiva@hotmail.com \\ 2 Universidade Federal Rural do Semi-Árido - UFERSA, Caraúbas-RN, Brasil, costa-joyce-alves@hotmail.com
}

\begin{abstract}
Resumo: As edificações, são expostas às intempéries do ambiente, e à utilização humana, tendendo a se degradar ao longo do tempo, tonando-se indispensável a manutenção do patrimônio. As falhas de projetos e execução, condições de uso, a falta de manutenção e os ambientes agressivos dão origem as manifestações patológicas. Vale ressaltar que medidas preventivas na fase de projeto e cuidados na execução podem minimizar a ocorrência dessas patologias, bem como representar uma grande economia em relação as recuperações. Analisou-se uma escola pública do município de Apodi-RN, escolhida em função da idade construtiva da edificação e devido seu sistema construtivo ser centrado em peças pré-fabricadas de argamassa armada. Objetivando identificar manifestações patológicas da edificação, identificando suas principais causas e mecanismos de prevenção e recuperação. $O$ estudo apresenta uma descrição literária das patologias que predominam na edificação, identificadas por meio de inspeção visual e realização de registros fotográficos. Os resultados demonstram que não há uma política de manutenção periódica na escola, resultando em diversas manifestações patológicas, e que a maior parte destas, poderiam ser evitadas com pequenos reparos e manutenção.O resumo deverá consistir numa descrição breve do conteúdo da comunicação.
\end{abstract}

Palavras-chave: Manutenção, Reparos, Patrimônio Histórico.

\section{Introdução}

A evolução nas técnicas, nos processos de construção das edificações e materiais empregados, tem ocorrido de forma acentuada nos últimos tempos, exigindo cada vez mais conhecimentos multidisciplinares por parte dos engenheiros, arquitetos e construtores em geral. (THOMAZ, 2001).

O processo de degradação de uma edificação, seja ele natural e/ou provocado por fatores, após a sua conclusão evolui ao longo do tempo em função do processo construtivo ou em decorrência do processo natural de envelhecimento. Entretanto, convém destacar que todas as etapas que uma edificação são interdependentes e relacionadas, assim, o desempenho da edificação, estar relacionada a tomada de decisão nas etapas do processo construtivo (PIRES, 2013).

As edificações, são expostas às intempéries do ambiente, e à utilização humana, tendendo a se degradar ao longo do tempo, tonando-se indispensável a manutenção do patrimônio. As falhas de projetos e execução, condições de uso, a falta de manutenção e os ambientes agressivos dão origem as manifestações patológicas. Vale ressaltar que medidas preventivas na fase de projeto e cuidados na execução podem minimizar a ocorrência dessas patologias, bem como representar uma grande economia em relação as recuperações.

A manutenção de uma estrutura é o conjunto de atividades necessárias para garantir o desempenho satisfatório ao longo do tempo dessa edificação, sendo assim, o conjunto de atividades que tenham a função de prolongar a vida útil da obra, a um custo compensador (Souza, 1998).

As manifestações patológicas tendem a intensifica-se com o passar do tempo, e um sintoma pode acarretar o desenvolvimento de outros problemas associados ao inicial, por exemplo: uma fissura provocada pelo 
momento fletor pode ocasiosar á corrosão das armaduras; flechas excessivas em vigas e lajes, podem originar fissuras em paredes e deslocamentos em pisos rígidos apoiados sobre os elementos fletidos (PIRES, 2013). a Sendo assim, as manifestações patológicas são também responsáveis por um percentual importante da manutenção. Parte das operações de manutenção nas edificações poderia ser evitada se houvesse um projeto com maiores detalhes e especificações do materiais e elementos adequados para a execução da obra. (COSTA JR, 2001).

Dessa forma, o estudo tem como objetivo analisar as manifestações patológicas que afetam a escola pública no Município de Apodi/RN, escolhida em função da idade construtiva da edificação e devido seu sistema construtivo ser centrado em peças pré-fabricadas de argamassa armada, com a finalidade de identificar suas prováveis causas e apontar mecanismos de recuperação.

\section{Metodologia}

O presente estudo foi realizado em uma escola pública do município de Apodi-RN, que foi construída na década de 90 e está em pleno funcionamento atualmente, com modalidade de ensino regular, em níveis de ensino fundamental e EJA (Educação de Jovens e Adultos), onde estão matriculados duzentos e oitenta alunos, nos turnos matutino e vespertino.

O edifício é composto por três pavimentos, onde estão localizadas salas de aula, sala de professores, refeitório, banheiros, biblioteca, secretária e diretoria. (Figura 1)

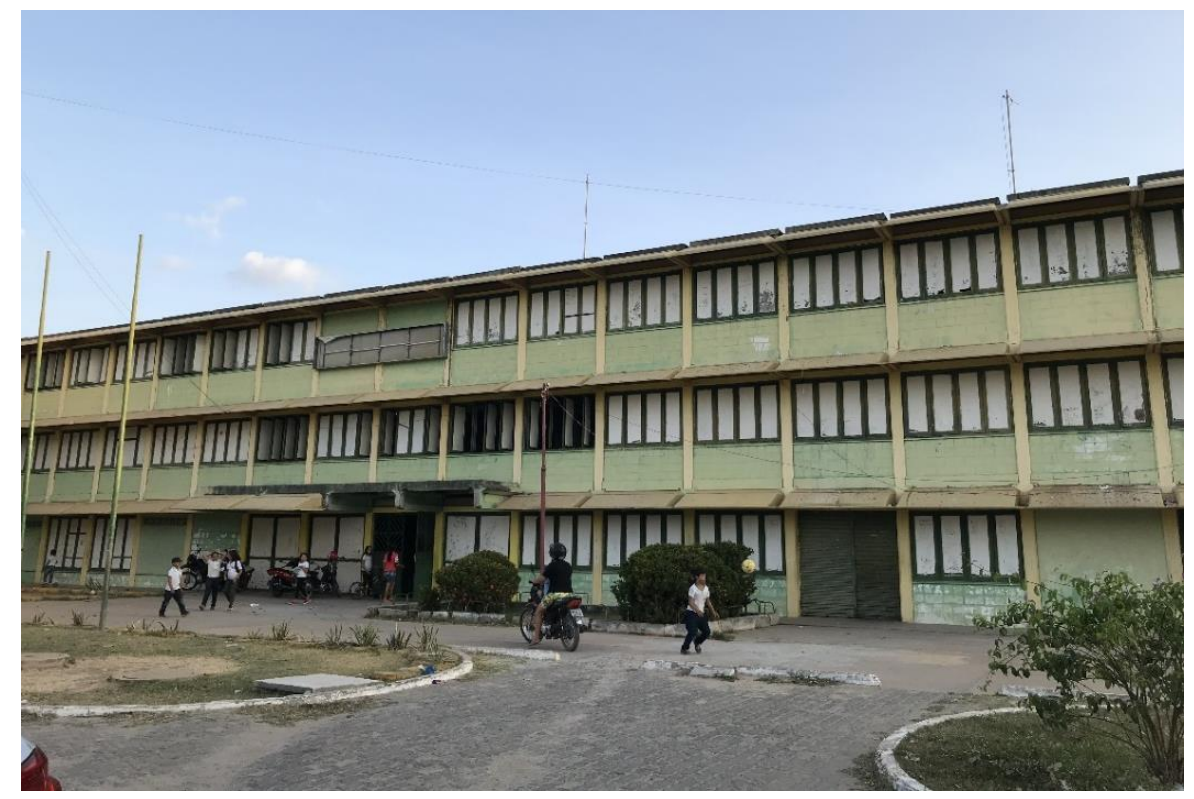

Figura 1 - Fachada da escola pública

A pesquisa baseia-se em um estudo de caso das manifestações patológicas existentes no edifício caracterizado anteriormente, onde através do levantamento visual foi possível fazer uma análise das patologias presentes e os prováveis motivos dos danos, enfatizando a relação com a importância da manutenção dos edifícios.

O estudo iniciou-se através de levantamento bibliográfico das principais manifestações patológicas em prédios e a necessidade de manutenção dos edifícios. Em seguida, foi realizado pesquisa de campo, onde foram realizadas observações no local identificando os fenômenos patológicos existentes. Neste momento, foram realizados registros fotográficos e interpretadas as manifestações patológicas presentes.

Após a identificação das patologias, e com base na pesquisa bibliográfica realizada, foi possível correlacionar quais foram às possíveis causas que geraram as patologias e tratamentos que podem ser empregados.

Além disso, foi observado os aspectos do prédio quanto a manutenção do edifício. Se o mesmo passa por procedimentos periódicos de manutenção ou possui algum sistema de manutenção, de acordo com as orientações disposta na NBR - 5674 sobre manutenção de edifícios.

Análise das manifestações patológicas em escola pública do município de Apodi/RN - Cinpar 2021 


\section{Resultados e discussões}

Durante a vistoria foi detectado algumas manifestações patológicas em diversos pontos da edificação, onde foi possível realizar breve discussão a respeito de possiveis causas e como pode ser corrigido o problema. Assim como foi realizado observações a respeito dos cuidados com a manutenção da edificação e se a mesma segue os procedimentos dispostos na NBR-5674:1999 - Manutenção de edifícios - Procedimentos.

Na edificação foi possivel identificar elementos estruturais como o pilar do refeitório, e escada localizada no pavimento térreo (Figura 2), que dar aceso ao pavimento superior, com desplacamento do concreto, armadura exporta e corrosão. Tal maniestação pode ser consequência da deficiência do cobrimento e/ou a baixa qualidade do concreto empregado, causando a exposição da armadura, outro fator agravante é a manutenção inadequada ou ausente.

Podendo ser tratado com a remoção do concreto solto e posterior eliminação da corrosão baseados em limpeza rigorosa sendo posteriormente realizando o reforço. E por fim, aplicar revestimento de proteção.

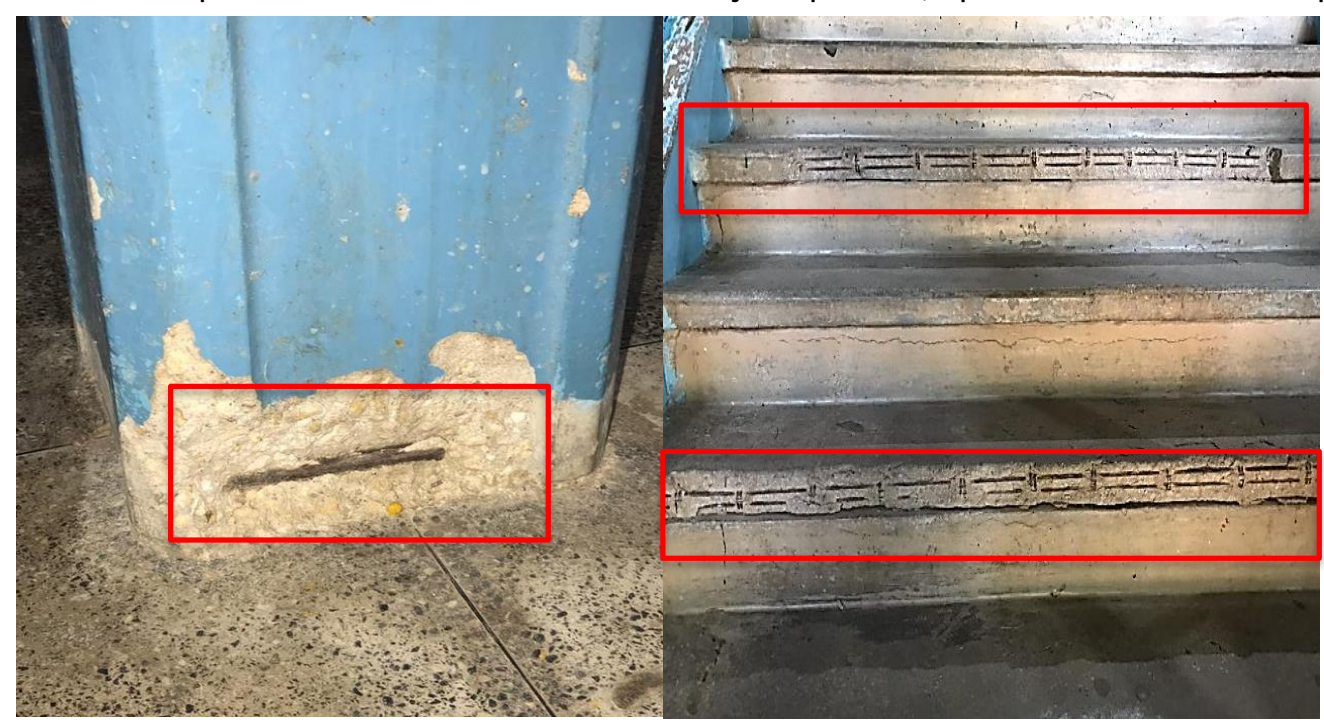

Figura 2 - Pilar do refeitório e escada do pavimento térreo da edificação

Na laje do pavimento térreo (Figura 3) apresenta um elevado grau de umidade, indicando a presença de bolor visto a coloração preta, além da armadura exporta e corrosão do aço da estrutura. A possível causa desses sintomas é uma infiltração no pavimento superior, favorecendo para o mecanismo de biodeterioração.

O problema pode ser tratado com a eliminação da infiltração, onde posteriormente o produto da corrosão nas armaduras deverá ser completamente removido, realizando uma limpeza rigorosa, com o uso de lixa, escova ou jato de areia. Posteriomente realizar uma pintura nas barras para uma maior proteção e preenchimento com argamassa de reparo.

Análise das manifestações patológicas em escola pública do município de Apodi/RN - Cinpar 2021 


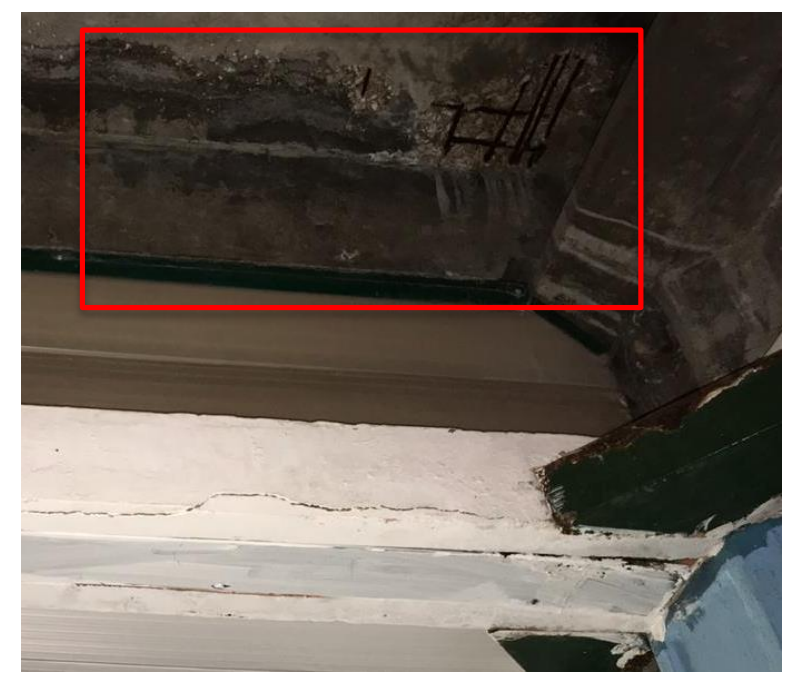

Figura 3 - Laje do pavimento térreo.

Outra mafinestação encontrada na edificação, foi fissuras em pilares (Figura 4), podendo ser decorrente da insuficiência de estribos, sobrecarga da armadura longitudinal e/ou flambagem da armadura longitudinal. Devido a fissura, a armadura pode está exposta a corrosão, o que pode ocasionar o aumento da mesma. Desse modo, deve-se verificar se a armadura está comprometida, e realizar reforço, se necessário.

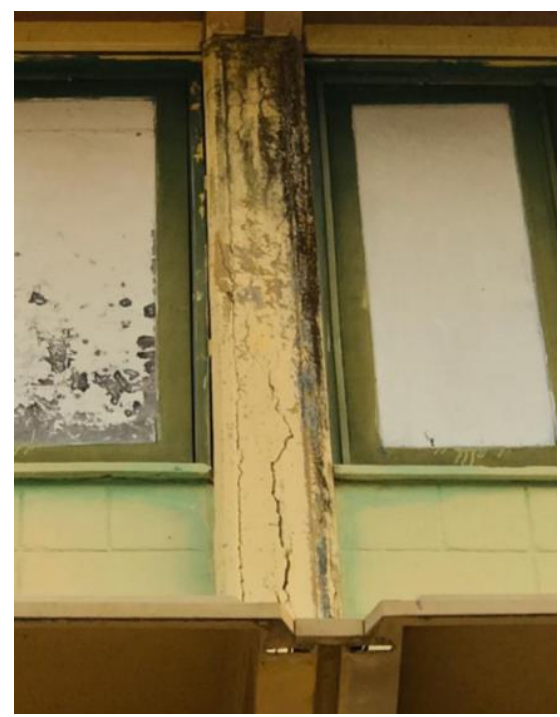

Figura 4 - Pilar externo a edificação

Obsrvou-se o descascamento da pintura da parede externa da edificação (Figura 5) . O problema pode ter sido ocasionado pela falta de preparação da superfície antes da pintura. Poeiras, pinturas antigas, são fatores que interferem na aderência da tinta. Outro fator preponderante é a ausencia de manutenção periódica na edificação. Desse modo, a manifestação em questão pode ser solucionado retirando a pintura mal aderida, e preparação da superfície para nova pintura.

Análise das manifestações patológicas em escola pública do município de Apodi/RN - Cinpar 2021 


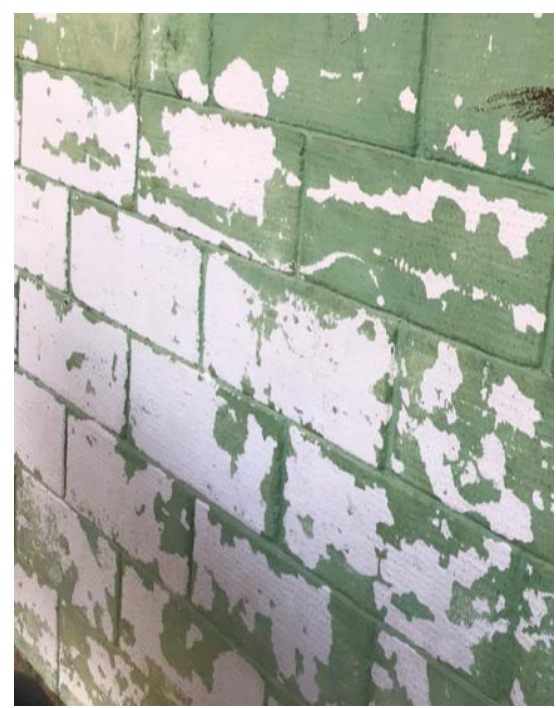

Figura 5 - Parede externa a edificação com descascamento da pintura

No refeitório da edificação constatou-se a ocorrência de destacamento cerâmico ( Figura 6) . A causa desse fenômeno pode ser decorrente da falta de aderência do material cerâmico ao substrato, assim como a falta de limpeza da superfície antes da aplicação do revestimento ou até mesmo a variação de temperatura. Desse modo, é necessário que os azulejos deslocados sejam removidos, realize-se a limpeza da superfície de aplicação e utilize novo revestimento.

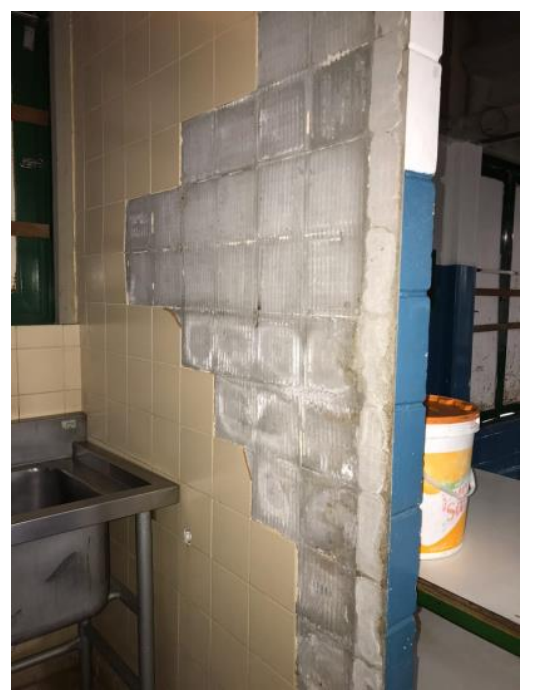

Figura 6 - Destacamento cerâmico no refeitório da edificação

Análise das manifestações patológicas em escola pública do município de Apodi/RN - Cinpar 2021 


\section{Conclusões}

De acordo com os resultados do presente estudo, a escola pública do munícipio de Apodi apresenta diversas manifestações patológicas em todo o edifício, as quais podem geram desconforto e insegurança aos usuários. Desse modo, a partir das análises realizadas com intuito de encontrar as possíveis causas e soluções para os problemas identificados, enfatizando a necessidade de manutenção dos edifícios, o prédio em estudo apresentou problemas superficiais e problemas mais graves que atingem a estrutura.

Diante dos fenômenos patológicos mais comuns, destacou-se a corrosão das armaduras e infiltração das lajes pela falta de impermeabilização, sendo estes problemas identificados em todos os pavimentos. Estes podem ser tradados pela identificação das infiltrações, impermeabilização das lajes, remoção do concreto comprometido, além da análise das armaduras e correto revestimento de proteção. Além disso, verificou-se que a escola não utiliza nenhum programa de manutenção, o que normalmente ocasiona o aumento dos fenômenos patológicos.

Desse modo, podemos concluir a importância da manutenção dos edifícios afim de garantir seu bom funcionamento, conforto e segurança aos usuários. Sendo este um procedimento que deve ser expandido e colocado em prático nas edificações.

\section{Referências Bibliográficas}

Associação Brasileira De Normas Técnicas. NBR 5674 - Manutenção de Edificações - Procedimentos. Rio De Janeiro, 1999. 6 P.

Costa jr, m. P. Avaliação pós-ocupação e manutenção estratégica de escolas públicas. 2001. Dissertação (Mestrado em engenharia civil) - universidade federal do espírito santo, espírito santo, 2001.

PIRES, J.R. Patologias na construção dos edifícios. Caso de estudo, edifício da FICASE na Cidade da Praia. 2013. 2285. Tese (Licenciatura) - Faculdade de Arquitectura. Universidade Jean Piaget de Cabo Verde, Palmarejo Grande, cidade da Praia, 2013.

Thomaz, e. Tecnologia, Gerenciamento e Qualidade na construção. 1a ed. São Paulo: PINI, 2001.

Souza, Vicente custódio de, Patologia, Recuperação e Reforço de Estruturas de Concreto. - São Paulo: PINI, 2009.

Análise das manifestações patológicas em escola pública do município de Apodi/RN - Cinpar 2021 